$\begin{array}{ll}\text { le portiQue } & \text { Le Portique } \\ \text { Revue de philosophie et de sciences humaines }\end{array}$

$30 \mid 2013$

Écrire sur l'art

\title{
Mémoires marranes
}

\section{Catherine Simon}

\section{OpenEdition}

\section{Journals}

Édition électronique

URL : http://journals.openedition.org/leportique/2664

DOI : $10.4000 /$ leportique.2664

ISSN : $1777-5280$

\section{Éditeur}

Association "Les Amis du Portique"

Édition imprimée

Date de publication : 18 juillet 2013

ISSN : 1283-8594

\section{Référence électronique}

Catherine Simon, « Mémoires marranes », Le Portique [En ligne], 30 | 2013, document 5, mis en ligne le 11 octobre 2013, consulté le 26 mars 2021. URL : http://journals.openedition.org/leportique/2664 ; DOI : https://doi.org/10.4000/leportique.2664

Ce document a été généré automatiquement le 26 mars 2021.

Tous droits réservés 


\title{
Mémoires marranes
}

\author{
Catherine Simon
}

\section{RÉFÉRENCE}

Paris, Seuil, « Collection du XXI ${ }^{\mathrm{e}}$ siècle, 2011, ISBN : 978-2-02-103871-2, 349 pages.

1 En présentant ce dernier volet - qui n'avait pas été prévu au départ - Nathan Wachtel réaffirme une option épistémologique, celle de mêler l'étude du présent à celle du passé. Est-ce par fidélité à Marc Bloch prônant une seule et même science de l'homme, unissant les vivants et les morts en passant des archives au terrain ? Le sujet, il faut le dire, s'y prête! Ne serait-ce à cause des qualités culturelles et particulières des itinéraires des sujets que notre auteur a choisi d'exposer ; par leurs agencements, entre souvenir et transmission, réminiscence et foi, persuasion et expression. Cette démarche, au fond, laisse entrevoir les linéaments de l'imbrication des différentes séquences et stances du temps poussées jusqu'à leur annulation. Ces annulations qui ouvrent sur des aboutissements fascinants par les violences engendrées, les marasmes occasionnées et les misères suscitées. Nous sommes là en présence d'une longue trame qui traverse les différents cœurs de notre modernité en ces centres violemment créatifs. Le marranisme, de ce point de vue, apparait comme un lieu emblématique, paradigmatique des identités conjuguées riches et néanmoins tendues qui nous font être.

2 Dans une première partie intitulée Contextes, l'auteur revient sur les événements de la conquête du Nordeste du Brésil, l'extermination des Indiens, l'esclavage des femmes et des enfants, les différentes fractions impliquées dans le contrôle du territoire, les forfaits des uns et des autres, bandits ou héros, les difficultés de l'installation, la rudesse du pays et l'attachement à la terre qui finit par advenir. Circonstances historiques et données géographiques - plusieurs photographies suggestives des paysages et de la végétation des différentes régions du sertão - nous instruisent sur les arrière-fonds des récits livrés dans la seconde partie de l'ouvrage (également des 
photographies de villages, de maisons ornées de symboles, de scènes de réunions, de personnes dument nommées).

3

Portraits? Itinéraires? Destins? Cheminements identitaires? Comment entendre et apprécier ces récits? Mais que reste-il donc de tous ces événements passés, sommesnous tentés de juger, dans un premier temps, en parcourant, les uns après les autres, ces récits individuels qui rapportent des rites anciens, l'observance d'interdits alimentaires, des souvenirs de coutumes, des généalogies, des quêtes spirituelles... Comment se dépose l'histoire en chacun d'entre eux ? Le dernier témoignage entretient la différence avec les autres dans l'élaboration d'une reconnaissance du passé, l'expression d'une mémoire et enfin l'apaisement identitaire. Toujours est-il qu'il ressort, à la lecture de ces récits, une sorte de trouble, qui serait à mettre sur le compte de l'émotion qui traverse les récits dont la mémoire inconsciente et le sentiment d'être différent tissent une des trames, également sur le compte de la complexité des postures qui appellent des arrangements entre foi et fidélité.

4 La part active que prennent Nathan Wachtel et, citons aussi, son épouse Jacqueline, à cette volonté de reprise du passé et d'entreprise d'avenir, est, à notre avis, insuffisamment qualifiée dans le présent document. Le lecteur devine qu'ils ont, sans doute, contribué à l'exposition sur l'«Art marrane dans le sertao" à la Maison de l'Amérique latine à Paris en 2003 mais qu'en est-il des différents séminaires et conférences qui seront donnés au Brésil?

Il reste qu'après La Foi du souvenir. Labyrinthes marranes (2001) et La logique des bûchers (2009), ce dernier volet Mémoires marranes inscrit bien «les études sur le marranisme dans la problématique générale de l'émergence d'une certaine modernité en Occident, en différents champs, tant celui de l'histoire socio-économique que dans celui des croyances religieuses ou de l'histoire intellectuelle. ». Et au lieu de paraphraser, citons un auteur familier de la revue Le Portique qui a déjà noté que «Le marrane comme figure ouvre, inaugure le temps des identités problématiques et sans cesse négociables ${ }^{1}$.

\section{NOTES}

1. Serge mвоuкоu, Messianisme et modernité. Dona Béatrice Kimpa Vita et le mouvement des Antoniens, Paris, L'Harmattan, p. 82. 